\title{
Degradation investigation in a postbuckling composite stiffened fuselage panel
}

\author{
A. C. Orifici ${ }^{1}$, R. S. Thomson ${ }^{2 *}$, R. Degenhardt ${ }^{3}$, A. Kling ${ }^{3}$, K. Rohwer ${ }^{3}$ and \\ J. Bayandor ${ }^{4}$ \\ ${ }^{1}$ School of Aerospace, Mechanical \& Manufacturing Engineering, Royal Melbourne Institute of Technology, GPO Box 2476V, Melbourne, \\ Victoria, 3001, Australia \\ ${ }^{2}$ Cooperative Research Centre for Advanced Composite Structures Limited, 506 Lorimer Street, Fishermans Bend, Victoria, 3207, \\ Australia \\ ${ }^{3}$ Institute of Composite Structures and Adaptive Systems, DLR - German Aerospace Center, Lilienthalplatz 7, 38108 Braunschweig, \\ Germany \\ ${ }^{4}$ The Sir Lawrence Wackett Centre for Aerospace Design Technology, Royal Melbourne Institute of Technology, GPO Box 2476V, \\ Melbourne, Victoria, 3001, Australia
}

\begin{abstract}
The European Commission Project COCOMAT (Improved MATerial Exploitation at Safe Design of COmposite Airframe Structures by Accurate Simulation of COllapse) is a currently running four-year project that aims to exploit the large strength reserves of composite structures through a more accurate prediction of collapse. Accordingly, one of the COCOMAT work packages involves the design of test panels with a focus on investigating the progression of composite damage mechanisms. This paper presents the collaborative results of some of the partners for this task. Different design alternatives were investigated for fuselage-representative test panels. Non-linear structural analyses were performed using MSC.Nastran (Nastran) and ABAQUS/Standard (Abaqus). Numerical predictions were also made applying a stress-based adhesive degradation model, previously implemented into a material user subroutine for Abaqus. Following this, a fracture mechanics analysis using Nastran was performed along all interfaces between the skin and stiffeners, to examine the stiffener disbonding behaviour of each design. On the basis of the structural and fracture mechanics analyses, a design was selected as being the most suitable for the experimental investigation within COCOMAT. Though the COCOMAT panels have yet to be manufactured and tested, experimental data on the structural performance and damage mechanisms were available from a separate project for a panel identical to the selected design. This data was compared to the structural, degradation and fracture mechanics predictions made using non-linear finite element solutions, and the application of the design within the COCOMAT project was discussed.
\end{abstract}

Keywords: Composite, postbuckling stiffened panels, skin-stiffener disbonding, COCOMAT.

\section{Introduction}

The European Commission Specific Targeted Research Project "Improved MATerial Exploitation at Safe Design of COmposite Airframe Structures by Accurate Simulation of COllapse" (COCOMAT), is a currently running four-year project involving fifteen international partners that aims to exploit the large strength reserves of postbuckling composite stiffened panels [1-2]. Currently, the onset of degradation in composite materials is not allowed, and composite structures must be designed with degradation occurring after the design ultimate load. The focus of COCOMAT is to produce a validated approach to include the effects of material degradation in the analysis, so that the final collapse of the structure can be more accurately predicted. This will allow composite structures to be designed with some degradation permitted, in a manner comparable to metallic structures where plasticity is already allowed between limit and ultimate loads. COCOMAT benefits from a high degree of synergy with the recently completed European Commission Framework Programme 5 project "Improved POst-buckling SImulation for Design of Fibre COmposite Stiffened Fuselage Structures" (POSICOSS), which similarly investigated the behaviour of fuselage-representative stiffened composite panels in compression, but did not include the effects of material degradation.

One of the work packages of the COCOMAT project is the design of fuselage-representative panels for experimental testing. Within this work package, the German Aerospace Center (DLR) and the Cooperative Research Centre for Advanced Composite Structures (CRC-ACS) are collaborating to produce panel designs with a specific focus on the experimental investigation into skin-stringer disbonding. This paper outlines the results of the collaborative research work so far, which includes the selection of a design most appropriate for the investigation of skin-stringer disbonding based on structural and fracture mechanics analyses. Though COCOMAT panels have not yet been manufactured and tested, a comparison is made between the numerical predictions and experimental testing data for an identical panel from a separate project.

* corresponding author: r.thomson@crc-acs.com.au 


\section{Panel Design}

\subsection{Panel Variations}

Based on previous experience [3], a nominal panel was defined, and three variations were proposed. These variations, V12, V15 and V16 all used identical material and boundary conditions, though had slight variations in geometry in order to investigate the effect of the number of stiffeners and the height of the outer stiffeners, see Fig. 1 and Table 1. The V12 design used four stiffeners with the outside two made $6 \mathrm{~mm}(43 \%)$ taller and stiffer than the nominal design, whereas the V15 and V16 design both used the nominal stiffener size, but differed in using five and six stiffeners respectively. FE models were generated for ABAQUS/Standard (Abaqus) and MSC.Nastran (Nastran), and are summarised in Table 2. The boundary conditions for all models were identical, with the axially loaded and fixed ends both fully clamped, and the resin-embedded or "potted" region on both ends represented as an area in which only axial displacement was permitted, based on Refs 3-4. The main difference between the Abaqus and Nastran models was in the representation of the skin-stiffener interface, where the Nastran models used only rigid links to connect the elements in the skin and stiffener flange, while the Abaqus model used rigid links connected to a thin layer of solid elements between the skin and flange to represent an adhesive layer.

\subsection{Analysis Approach}

The three panel variations were analysed with implicit solvers using a full Newton-Raphson procedure [5], where the default nonlinear parameters of both software packages were used, except for a STABILIZE parameter of $2 \times 10^{-6}$ in Abaqus and a convergence tolerance level of "Very High" in Nastran. The STABILIZE parameter functions similar to a viscosity in Abaqus, where the addition of the factor reduces some of the energy of the panel to assist with convergence issues, and the "Very High" setting in Nastran corresponds to load and work residuals of $1 \times 10^{-3}$ and $1 \times 10^{-7}$ respectively. All panels were analysed to $4 \mathrm{~mm}$ axial compression, except for the Nastran V15 and V16 models, which only ran to $3.54 \mathrm{~mm}$ and $3.51 \mathrm{~mm}$ axial compression respectively due to convergence problems.

For the Nastran models, use was made of a tool developed previously, Compdat [6], to calculate strain energy release rates $(G)$ at all the skin-stiffener interfaces. The values of $G$ in its mode I and II components were used in a mixed mode failure law, given in Eq. (1), to determine the likelihood of skin-stiffener disbond initiation. In order to do this, values of $G_{\text {Ic }}$ and $G_{\text {IIc }}$ for the IM7/8552 material system were required, which were taken from Refs 7 and 8, respectively, and are given in Table 3. The stiffeners in each panel were numbered starting from the topmost stiffener, as viewed in the XY plane, and skin-stiffener interfaces were designated as upper or lower for each stiffener in the same plane. The numbering system for all models is given in Fig. 2, where $\mathrm{S}$ is the stiffener number, $\mathrm{I}$ is the interface designation, and $\mathrm{U}$ and $\mathrm{L}$ are upper and lower, respectively. For each model, the sensitivity of the disbond predictions to the exponents of the mode I and II ratios ( $m$ and $n$ in Eq. (1), respectively) in the mixed mode failure law was also investigated.

$$
\left(\frac{G_{\mathrm{I}}}{G_{\mathrm{Ic}}}\right)^{m}+\left(\frac{G_{\mathrm{II}}}{G_{\mathrm{II} \mathrm{c}}}\right)^{n} \leq 1
$$

\subsection{Analysis Results}

The load-shortening graphs for designs V12, V15 and V16 are given in Figs 3 to 5, respectively. The agreement between Nastran and Abaqus results was very good, particularly for the local buckling. All designs were predicted to buckle into the same local buckling mode shape at an axial compression between 0.53 and $0.57 \mathrm{~mm}$, which involved 15 longitudinal half sine waves per stiffener bay. The global buckling patterns of all panels were symmetrical, with all panels buckled inwards towards the centre of curvature. The V12 panel, with three stiffener bays, developed a single central global buckle at around $1.25 \mathrm{~mm}$ axial compression, whilst the V15 and V16 panels, with four and five stiffener bays respectively, showed two global buckles in the outer stiffener bays developing at around $1 \mathrm{~mm}$ axial compression. Also, the $\mathrm{V} 12$ panel transitioned from local to global buckling via an anti-symmetric mode, and both the V12 and V16 panels showed a change to a secondary global buckling shape.

The results for failure prediction based on SERR and the mixed mode failure criterion with two sets of power law exponents are summarised in Table 4, where failure is used here to mean the onset of skin-stringer disbonding, and not the final structural collapse of the panel. Failure was predicted to initiate at the edge 
stiffeners in design V12 and at the centre stiffeners for V15 and V16. The axial compression value for failure was very consistent across the three designs ranging from $1.39 \mathrm{~mm}$ to $1.44 \mathrm{~mm}$ for the indices $m=1$ and $n=1$. Changing the power law indices to $m=0.2$ and $n=1$ reduced the axial compression at failure by up to $17 \%$ for V16. In general, the predicted failure was Mode I dominated.

\subsection{Design Selection}

As a result of the structural and fracture mechanics analyses on all proposed panels, panel design V15 was recommended as being best suited for experimental investigation of skin-stiffener disbonding. For this panel, the postbuckling behaviour was stable with a progressive change from local to a symmetric global buckling mode. The panel also exhibited a large stable global postbuckling zone from $0.96 \mathrm{~mm}$ to $3.45 \mathrm{~mm}$ axial compression, and stiffener disbonding was predicted to initiate clearly after global buckling. Finally, this panel showed the least sensitivity to the mixed mode power law exponents for the predicted axial compression at failure initiation.

In contrast, the V12 panel analysis predicted that disbonding would initiate in the outer stiffeners first, which raises the possibility that disbond initiation could lead to catastrophic failure of the panel. Additionally, the progression from local to global buckling via an anti-symmetric global mode demonstrated less stable global buckling behaviour. Also, disbond initiation was predicted to coincide with the change from local to global buckling, which would make the accurate detection of initiation difficult during testing.

Separately, the V16 panel analysis predicted a reduced postbuckling zone as compared with the V15 panel, due to the secondary mode shape change occurring at $2.5 \mathrm{~mm}$ axial compression. This postbuckling mode shape change would not only be complicated by the existing skin-stiffener disbond, but would affect the investigation into disbond growth. The disbond initiation prediction for the V16 panel was also more sensitive to the power law exponents, which would make validation of degradation models more difficult.

\section{Experimental Testing}

Though the COCOMAT test panels have yet to be manufactured and tested, experimental results were available as part of a separate DLR project on a panel identical to the selected design. These experimental results are summarised in Fig. 6 and in the first row of Fig. 9, which respectively show the load versus axial compression (load-shortening) values taken from between the loading platens, and deformation patterns obtained from photogrammetric measurement conducted. Note that where possible the figures of deformation patterns were taken just after points mode shape change, and that all images face the stiffener side of the panel. The test procedure involved pre-test loadings to settle experimental non-linearities and calibrate the measuring equipment, then quasi-static loading until collapse. After the occurrence of global buckling the loading was briefly stopped to inspect the panel and perform subsequent measurements, the effect of which is seen in a slight reduction in the panel load at around $1.34 \mathrm{~mm}$ axial compression.

Under loading, the panel underwent local buckling of 15 longitudinal half sine waves per stiffener bay at an axial compression of $0.51 \mathrm{~mm}$. This deformation pattern was slightly asymmetric, with one side of the panel moving towards and the other side moving away from the centre of curvature, where the outwards moving edge corresponds to stiffener 5 in Fig. 2(b). First global buckling occurred at $74.4 \mathrm{kN}$ or $0.97 \mathrm{~mm}$ compression, with an asymmetric deformation pattern of two global buckles in the outer stiffener bays consisting of the same inward and outward global buckles. A secondary global buckling shape developed at around $1.72 \mathrm{~mm}$ compression, where the inward global buckle grew to the adjacent inner stiffener bay. The collapse of the panel occurred at $83.6 \mathrm{kN}$ or $2.71 \mathrm{~mm}$ axial compression, and was characterised by an extreme aural event, and a sharp reduction in the load carrying capacity of the panel.

From visual inspection, the failed panel showed a variety of composite damage mechanisms, including fibre fracture in both the stiffener blade and flange, matrix cracking in the skin and stiffener blade and flange, and multiple delaminations in the region between the skin and stiffener and between ply groups in the stiffener blade, see Fig. 7. The collapse of the panel was likely due to fibre fracture across the blade in the centre of the stiffener 5, located at the edge of the outward global buckle. There were also regions of significant separation between the skin and stiffener where the stiffener buckled locally away from the skin, in both the centre of the middle stiffener (stiffener 3 ) and close to the potting in one of the inner stiffeners (stiffener 4 ) on the nonloading side.

\section{Comparison of Results}

In addition to the design calculations, an FE model with geometric imperfections was created by applying panel imperfections from the photogrammetric measurement of the unloaded panel to the V15 Nastran model. As an 
additional numerical comparison, the V15 Abaqus model was also analysed with a degradation methodology previously developed and implemented using the Abaqus USDFLD material user subroutine [9]. The subroutine was applied to the elements of the adhesive between the skin and stiffener, and monitored maximum stress failure criteria coupled to corresponding stiffness reductions upon satisfaction of the criteria as a means of modelling degradation in the skin-stiffener interface. The strength properties of the adhesive were taken from manufacturer data sheets [10] and are summarised in Table 5. For the USDFLD, a value of $0.1 \%$ was used as the reduction factor for the stiffness properties, on the basis of a parametric study and on the assumption that a value as close to zero as numerically possible was required in order to simulate the loss of load-carrying capacity by the adhesive upon failure. These computations were performed prior to the experimental testing, though were not used as part of the panel selection process, and the results using the $0.1 \%$ reduction are included only for comparative purposes. The load-shortening and deformation progression of the imperfect and USDFLD models are given in Figs 9 to 10, respectively, which also include the Nastran and Abaqus solutions from the design analyses. Note that the Nastran imperfect model was only run to $3.0 \mathrm{~mm}$ axial compression to save computational time, to avoid the structural collapse between $3.0 \mathrm{~mm}$ and $4.0 \mathrm{~mm}$ compression that caused significant convergences problems and more than doubled the total computation time.

Comparing models without degradation, all solutions gave excellent predictions of the panel stiffness and local buckling mode shapes compared to the experimental results. The addition of the skin imperfections had an almost negligible effect on the results, with only the transition from local to global buckling showing slight difference, though this result is to be expected as the behaviour of the stiffened panels is dominated by the stiffeners and not the skin. All solutions showed very good comparison with the first global buckling mode shape and initial postbuckling stiffness, though the experimental first global buckling load was slightly less than that predicted, and the asymmetry in the experimental deformation pattern was also not seen in the numerical results. All models predicted a similar initial postbuckling mode shape of two global buckles in the outer stiffener bays, though significantly the asymmetric inward/outward deformation pattern of the experiment was not seen in the numerical results, as all models predicted two inwards global buckles. The experimental panel underwent a secondary mode shape change, and whilst all models predicted a similar change, the asymmetry seen in the experimental panel was again not predicted. As a result of this there is significant difference between the load and axial compression of the secondary mode shape change, the stiffness following this change, and the collapse load and axial compression values of the experiment and numerical results. Additionally, the skinstiffener disbonding predicted as part of the design analysis was not seen in the experiment, and although cracking was heard prior to global buckling to indicate some damage event was occurring, skin-stiffener disbonding was only visible after the panel had collapsed. The predicted location of disbonding, in the middle of the centre stiffener, did however agree well with the experiment, though the additional skin-stiffener disbonding close to the potting region was not predicted.

For the Abaqus model with the degradation subroutine applied, failure in the adhesive is predicted to occur at an axial shortening of around $0.71 \mathrm{~mm}$, occurring first at the inside interface of one of the inner stiffeners (S2) approximately $20 \mathrm{~mm}$ from the potting on the loading side. By $0.78 \mathrm{~mm}$ axial compression failure was predicted to have initiated at the four innermost stiffener interface, all at elements $20 \mathrm{~mm}$ from the potting. Under further loading the number and growth of failed elements increased rapidly, and by first global buckling at $1.01 \mathrm{~mm}$ axial compression almost all of the three inner stiffeners and half of both the outer stiffeners were predicted to have failed. This prediction of damage did not correlate well with the experiment, as the experimental panel only showed two regions of local skin-stiffener disbonding, and not an almost total failure of all adhesive regions as was predicted. In spite of this, the Abaqus USDFLD model showed close comparison with the experimental load-shortening results across the entire loading regime except for the final structural collapse. This is seen in the predictions of load, axial compression and stiffness before and after the onset of global buckling showing quite good agreement with experiment. Although the USDFLD model predicted a number of different postbuckling mode shapes, all involved a large central global buckle and this did not compare well with the experiment.

\section{Discussion}

The inability of any of the models to capture the asymmetry seen in the experimental buckling shapes is the most significant factor affecting all numerical predictions, and this may be due to a number of reasons. Firstly, the panel is susceptible to slight shape changes at the panel edges such as bending and warping as a result of the manufacturing and curing process, and without longitudinal edge supports these global geometric imperfections at the panel edge are likely to directly influence the panel buckling shapes. Evidence of this can be seen in the experimental results, where even in local buckling an asymmetric displacement pattern is evident. Another reason for the asymmetric buckling shapes may be the influence of imperfections in the stiffener blade width, where from inspection of the panel after the experiment it was noticed that the manufactured blade width varied throughout the panel. Whilst it is unlikely that any of the stiffeners were manufactured with such significantly 
lower thickness so as to affect the buckling shapes, it does suggest that without longitudinal edge supports the panel may be more sensitive to variations in the stiffener blade width and asymmetrical geometric imperfections in general. A third reason for the asymmetry in the experiment may be due to an asymmetric introduction of the load, as a result of the potting edges not being parallel, and though there did not appear to be any asymmetry in the axial displacements from the photogrammetric images, a detailed analysis of the strain gauge data would be required in order to determine whether this occurred.

The fact that the USDFLD model gave close predictions of the load-carrying capacity of the panel in spite of almost completely misrepresenting the composite damage mechanism and postbuckling mode shapes signifies the importance of incorporating some form of degradation into the analysis for these types of panels. As has been noted in previous COCOMAT benchmarking studies [11] and separately from other researchers [12-14], numerical approaches that do not account for the degradation in panel performance caused by composite damage mechanisms consistently overestimate panel behaviour, especially in the deep postbuckling region. Though the reduction in load-carrying capacity of the experimental panel was most likely due to the asymmetric deformation causing mode shapes of lower structural stiffness, the USDFLD provided a mechanism to incorporate this type of reduction into the analysis. This indicates that the degradation approach of the USDFLD may have value in the design process for these types of structures as a means of obtaining a rough approximation to the real loadcarrying capacity, though this may be specific to this particular test panel design or to panels without longitudinal edge restraints.

In terms of the COCOMAT project, the results of this research work will be compared to results for COCOMAT panels yet to be manufactured and tested. These panels will have a more thorough manufacturing and testing procedure, which notably will include the measurement of geometric imperfections using a separate system and a manufacturing technique to ensure parallelism in the potted ends. This will make the reasons for any future asymmetric panel deformations easier to determine, and should improve the quality of the numerical predictions. Additionally, degradation models that more accurately represent the composite damage mechanisms are under development as part of the COCOMAT project, and the results of this work will be compared to these approaches.

\section{Conclusion}

A test panel for the investigation of skin-stiffener disbonding in fuselage-representative structures was designed and analysed, as a result of collaborative work between DLR and CRC-ACS in the European Commission Project COCOMAT. In the design process, different panel variations were investigated, and following non-linear structural analysis in Nastran and Abaqus, and linear elastic fracture mechanics analyses of the disbonding likelihood of all skin-stiffener interfaces, a suitable design was recommended.

As COCOMAT panels are yet to be manufactured, experimental data for the load-shortening and deformation patterns were taken from testing from a separate project of a panel identical to the one recommended. This experimental data was compared to the structural, degradation and fracture mechanics predictions, where all models gave excellent predictions up to the onset of first global buckling, with only fair predictions in the postbuckling region. Skin-stiffener disbonding was only seen in the experimental panel upon collapse, and this did not agree with the prediction of both the fracture mechanics and a separate stress-based degradation model, though of the two the fracture mechanics results predicted accurately the location of disbonding and gave a more realistic picture of the composite damage.

The most significant factor adversely affecting further agreement between the experimental and all numerical results is the development of asymmetric deformation patterns in the experiment, which represented a significantly weaker structural configuration than the symmetric deformation patterns predicted by the numerical models. This experimental asymmetry was likely due to the panel being susceptible to global geometric imperfections, as longitudinal edge restraints were not used, though may also have been the result of variations in the stiffener width and an asymmetric load introduction.

The results of this research work will be compared to results for COCOMAT panels yet to be manufactured and tested, as well as to predictions using alternative degradation models that are currently under development.

\section{Acknowledgments}

The authors would like to acknowledge the financial support of: the European Commission, Priority Aeronautics and Space, Contract AST3-CT-2003-502723; the Australian Postgraduate Awards Scheme; the German Academic Exchange Service, and; the Australian Government under the "Innovation Access Programme - 
International Science and Technology". The authors would also like to acknowledge Prof. Murray Scott of the CRC-ACS for support within the COCOMAT project.

\section{References}

1. Degenhardt R, Rolfes R, Zimmermann R, Rohwer K. COCOMAT - Improved MATerial Exploitation at Safe Design of COmposite Airframe Structures by Accurate Simulation of COllapse. In: Proceedings of the International Conference on Buckling and Postbuckling Behaviour of Composite Laminated Shell Structures, Eilat, Israel, March 1-2 2004.

2. COCOMAT Home Page, www.cocomat.de, 2005.

3. Klein H, Zimmerman R, Kling A. Buckling and postbuckling of stringer stiffened fibre composite curved panels - tests and computations. In: Proceedings of the International Conference on Buckling and Postbuckling Behaviour of Composite Laminated Shell Structures, Eilat, Israel, March 1-2 2004.

4. Abramovich H, Grunwald A, Pevsner P, Weller T, David A, Ghilai G, Green A, Pekker N. Experiments on axial compression postbuckling behavior of stiffened cylindrical composite panels. In: Proceedings of the $44^{\text {th }}$ AIAA/ASME/ASCE/AHS Structures, Structural Dynamics and Material Conference, Norfolk, VI, USA, AIAA paper No. 2003-1893, 2003.

5. Crisfield MA. Non-linear finite element analysis of solids and structures: Vol 1. New York, NY: Wiley, 1991.

6. Yap JWH, Scott ML, Thomson RS, Hachenberg D. The analysis of skin-to-stiffener debonding in composite aerospace structures. Composite Structures 2002;57:425-435.

7. Schön J, Nyman T, Blom A, Ansell H. A numerical and experimental investigation of delamination behaviour in the DCB specimen. Composite Science and Technology 2000; 60:173-184.

8. Schön J, Nyman T, Blom A, Ansell H. Numerical and experimental investigation of a composite ENFspecimen. Engineering Fracture Mechanics 2000;65:405-433.

9. Reinsch A, Degenhardt R. Numerical finite-element-analysis of degradation in stiffened CFRP panels. DLR Internal Report 1B 131-2005/34, Institute of Composite Structures and Adaptive Systems, DLR Braunschweig, 2005.

10. Hexcel Composites. Redux ${ }^{\circledR} 312$ Product Data. www.hexcel.com, 2005.

11. Orifici AC, Thomson RS, Gunnion AJ, Degenhardt R, Abramovich H, Bayandor J. Benchmark finite element simulations of postbuckling composite stiffened panels. In: Proceedings of the Eleventh Australian International Aerospace Congress (AIAC-11), Melbourne, 13-17 March 2005.

12. Agarwal BL. Postbuckling behavior of composite shear webs. AIAA Journal 1981;19(7): 933-939.

13. Knight Jr NF, Starnes Jr JH. Postbuckling behaviour of selected curved stiffened graphite-epoxy panels loaded in axial compression. AIAA Journal 1988;26(3):344-352.

14. Singer J, Arbocz J, Weller T. Buckling experiments, experimental methods in buckling of thin-walled structures. Volume 2, Shells, built-up structures, composites and additional topics. John Wiley \& Sons, Inc., New York, 2002. 


\section{Figures}

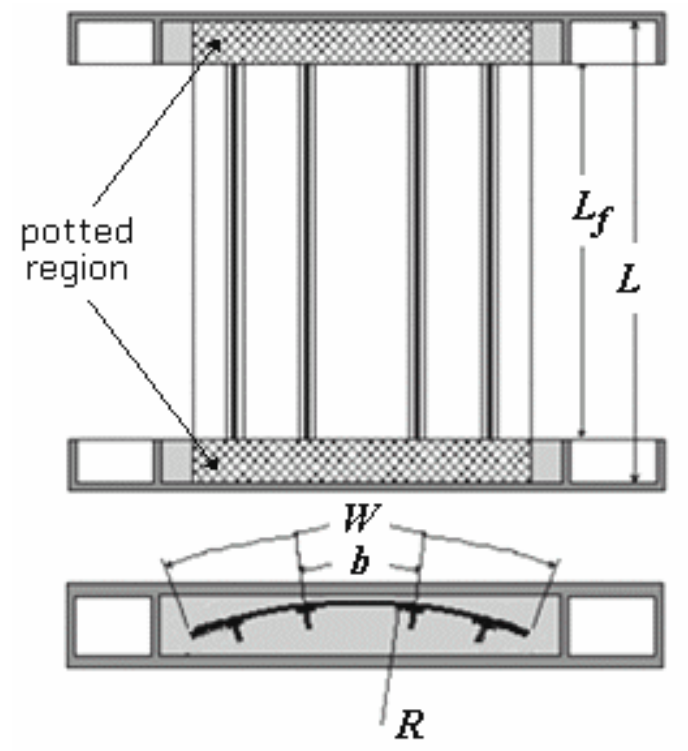

(a)

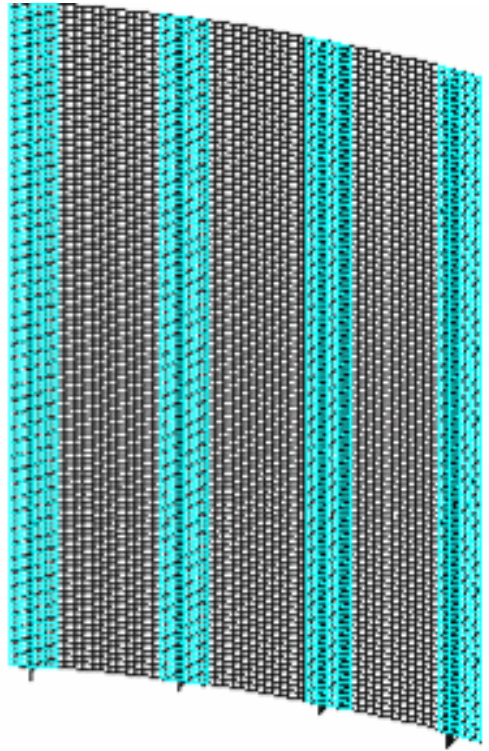

(b)

Fig. 1: Nominal panel design (a) geometry (b) Abaqus FE model
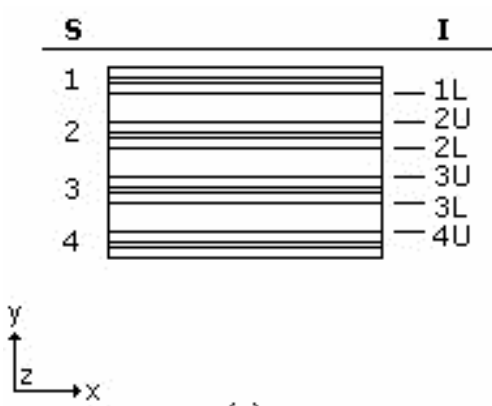

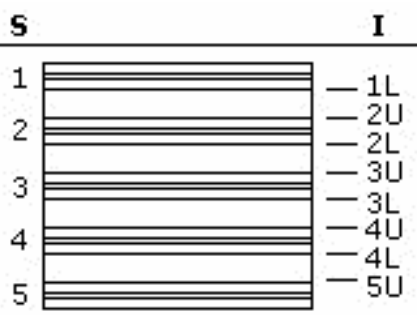

(b)

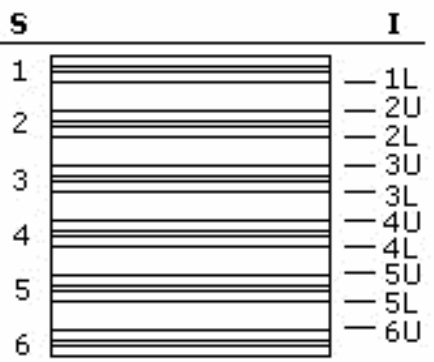

(c)

(a)

Fig. 2: Skin-stiffener groups: (a) V12 (b) V15 (c) V16

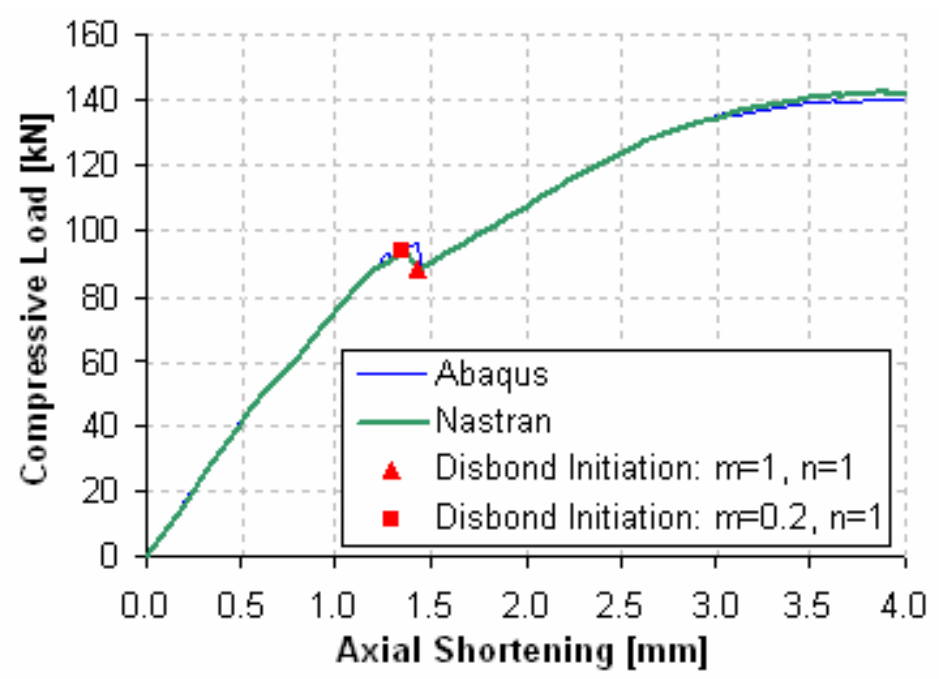

Fig. 3: V12 load-shortening, Abaqus and Nastran solutions 


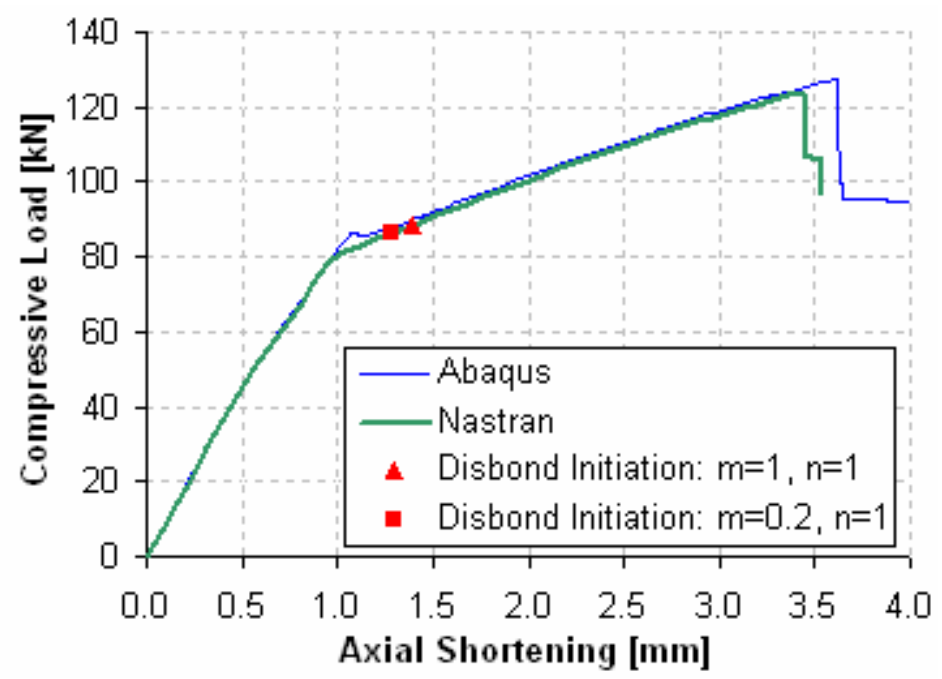

Fig. 4: V15 load-shortening, Abaqus and Nastran solutions

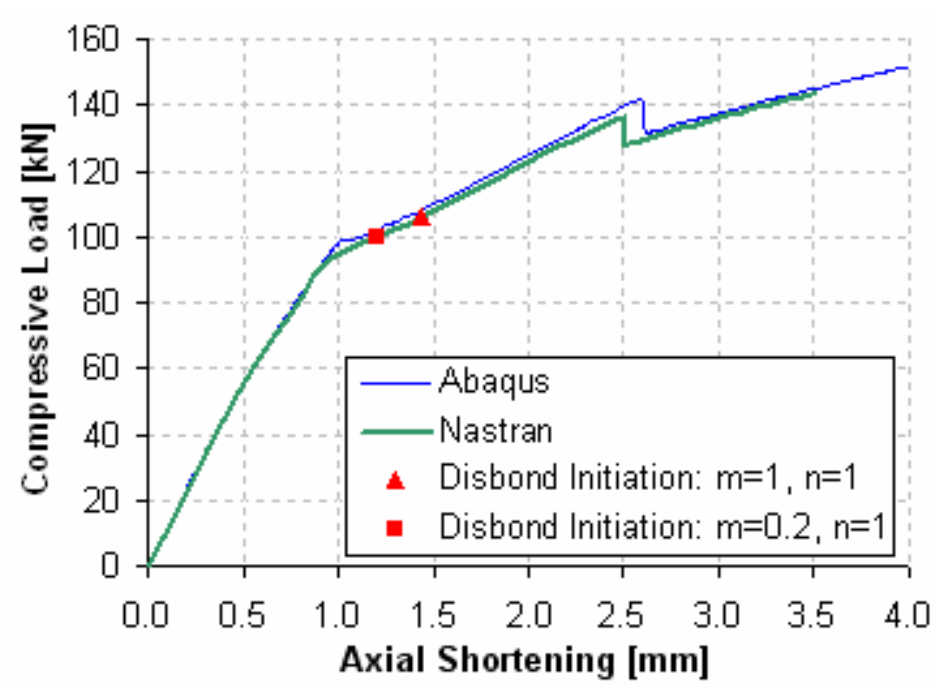

Fig. 5: V16 load-shortening, Abaqus and Nastran solutions

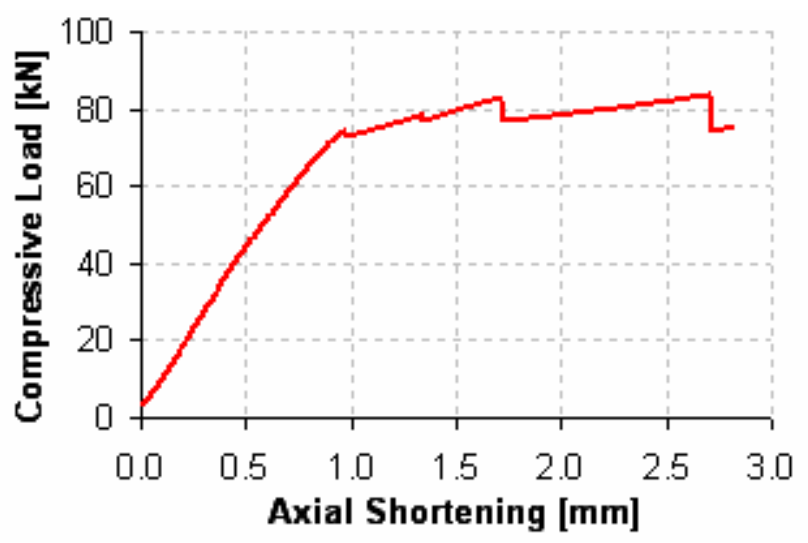

Fig. 6: Experimental load-shortening graph 


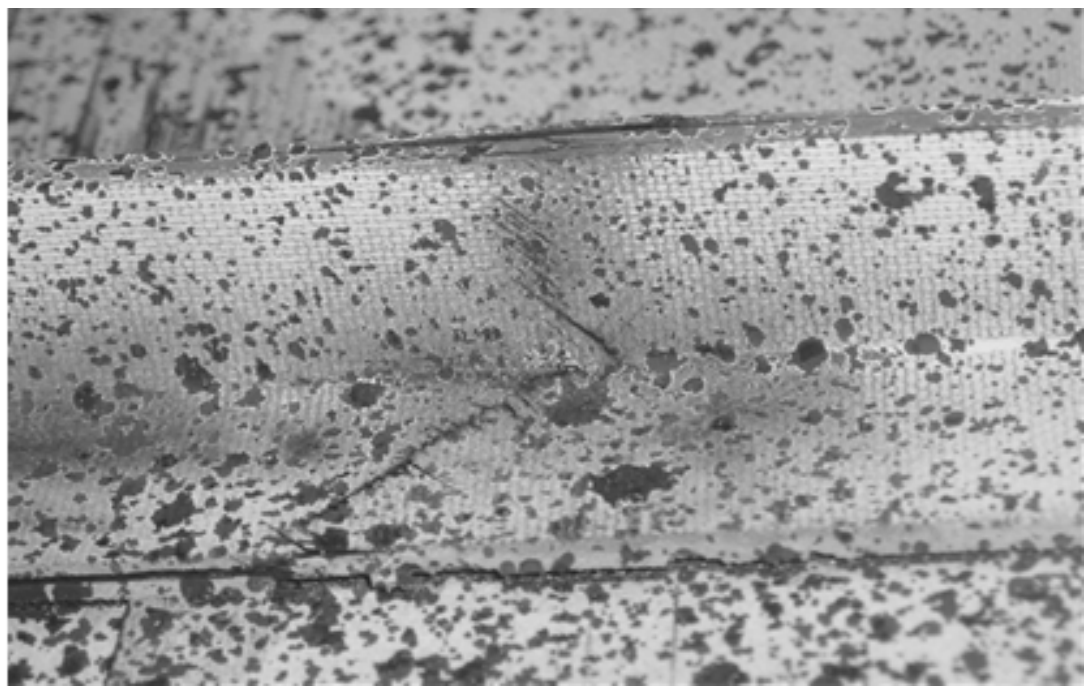

Fig. 7: Disbonded region in central stiffener, unloaded after collapse, showing composite damage mechanisms present from visual inspection throughout the panel: Delamination, fibre fracture and matrix cracking in the stiffener blade, fibre fracture and matrix cracking in the stiffener flange, multiple delaminations between the skin and stiffener, and matrix cracking in the skin

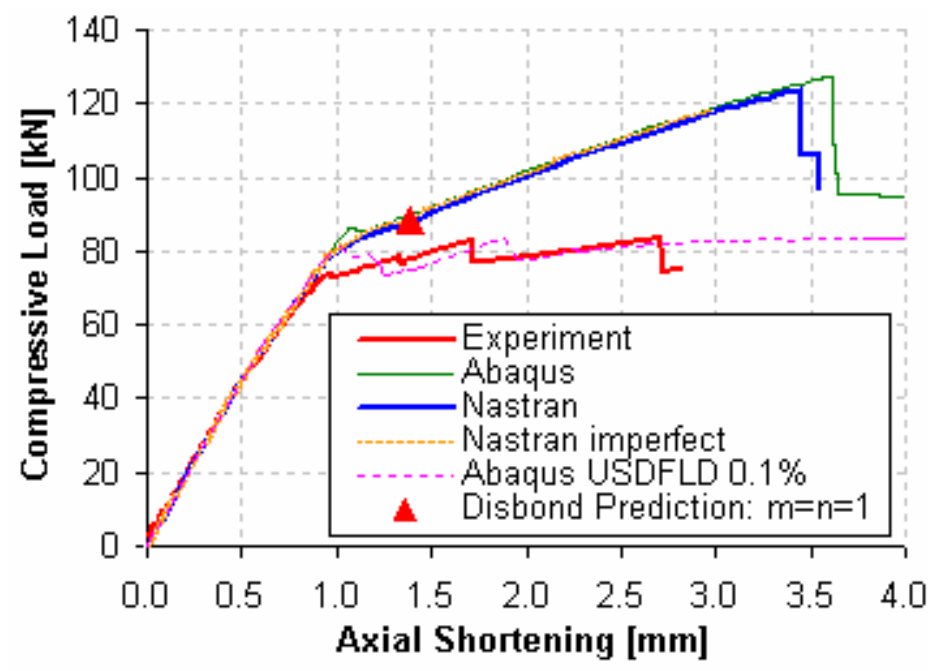

Fig. 8: Load-shortening graph, experiment vs numerical predictions 

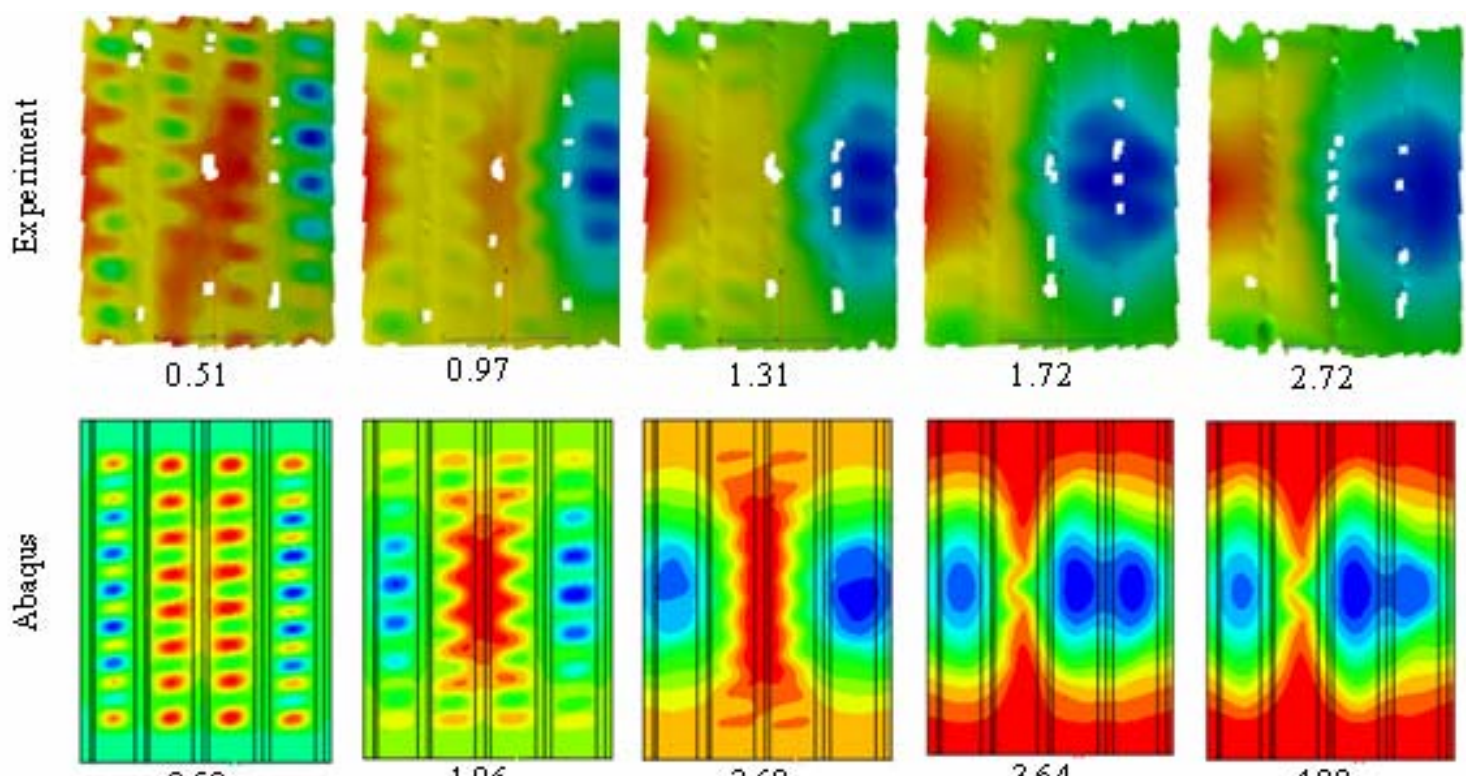

1.31

1.72

2.72
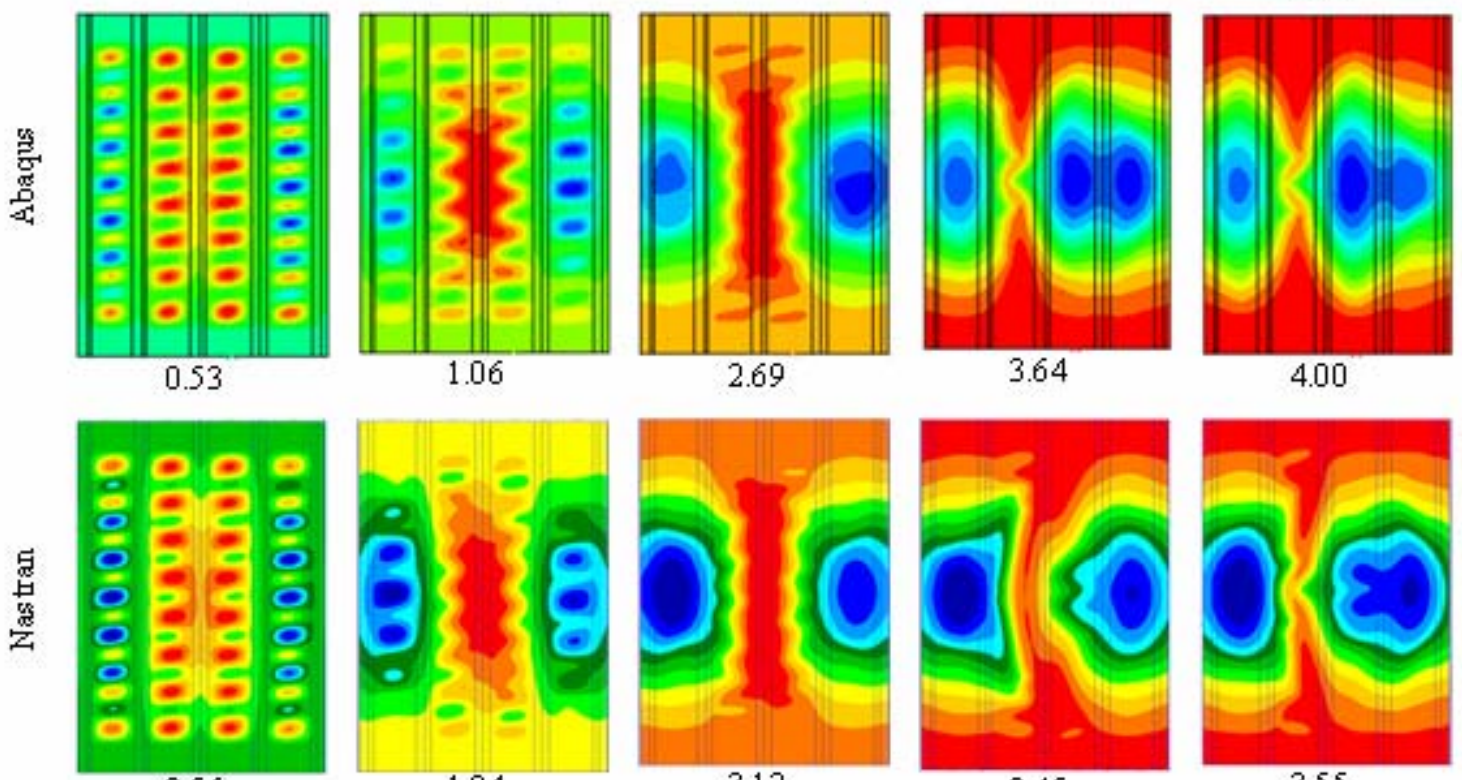

3.12
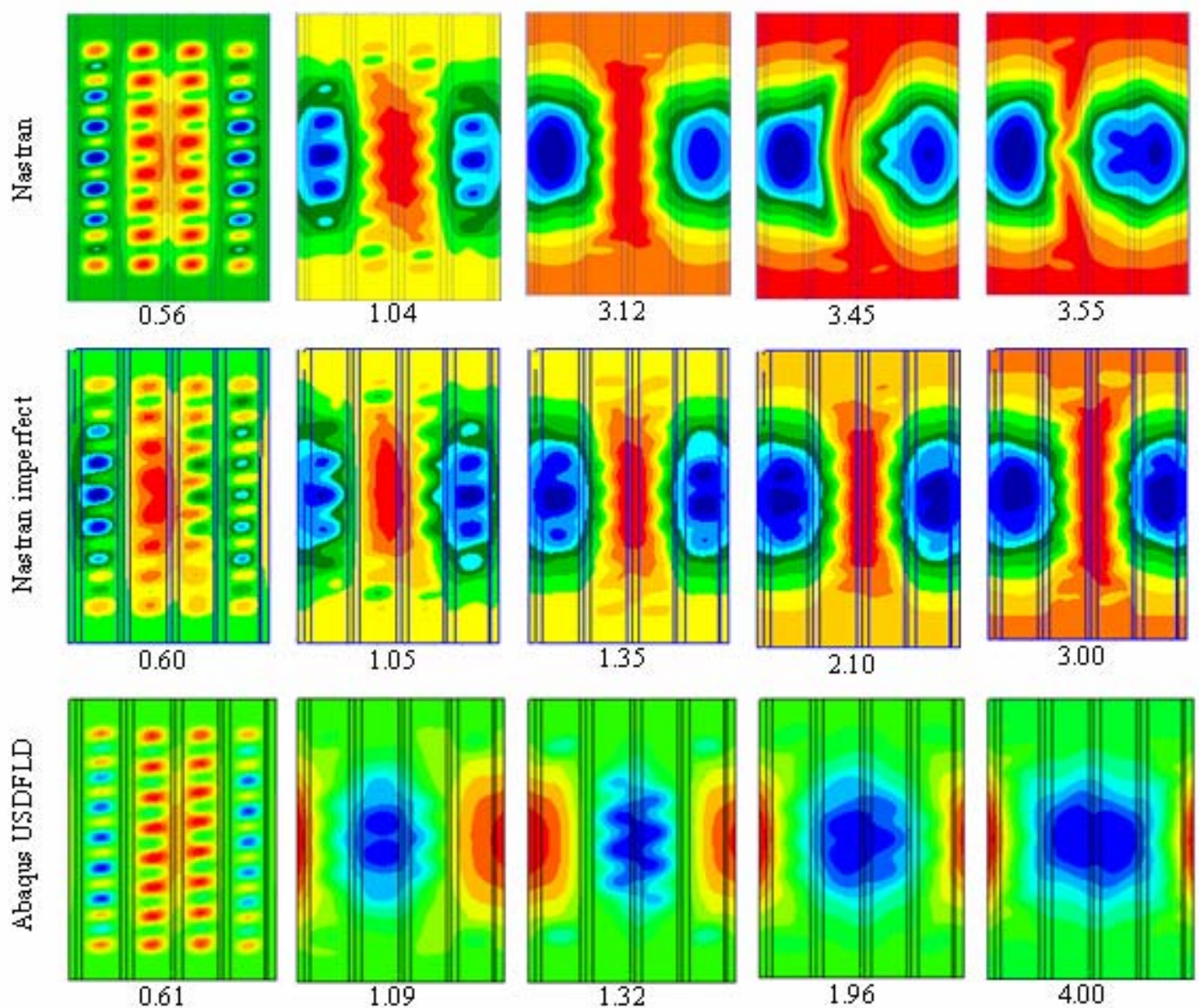

Fig. 9: Experimental and numerical deformation patterns at various values of axial compression [mm], viewed facing stiffener side 
Tables

Table 1: Panel parameters, all designs

\begin{tabular}{llll}
\hline Parameter & Panel design & & \\
& V12 & V15 & V16 \\
\hline Panel length, $L$ & 780 & 780 & 780 \\
Panel free length, $L_{f}$ & 660 & 660 & 660 \\
Panel radius, $R$ & 1000 & 1000 & 1000 \\
Stiffener pitch, $b$ & 129 & 129 & 129 \\
Number of stiffeners & $4(2$ inner, 2 outer $)$ & 5 & 6 \\
Panel arc length, $W$ & 420 & 560 & 698 \\
Material system & IM7/8552 & IM7/8552 & IM7/8552 \\
Skin lay-up & {$[90, \pm 45,0]_{\mathrm{S}}$} & {$[90, \pm 45,0]_{\mathrm{S}}$} & {$[90, \pm 45,0]_{\mathrm{S}}$} \\
Stiffener height & inner: 14 & 14 & 14 \\
outer: 20 & inner: $\left[(45,-45)_{3}, 0_{6}\right]_{\mathrm{S}}$ & {$\left[(45,-45)_{3}, 0_{6}\right]_{\mathrm{S}}$} & {$\left[(45,-45)_{3}, 0_{6}\right]_{\mathrm{S}}$} \\
Stiffener web lay-up & outer: $\left[(45,-45)_{3}, 0_{8}\right]_{\mathrm{S}}$ & & 0.125 \\
Ply thickness & 0.125 & 0.125 & 32 \\
Stiffener width & 32 & 32 & \\
\hline
\end{tabular}

Table 2: FE model parameters, all designs

\begin{tabular}{lllllll}
\hline Number of elements & Abaqus & \multicolumn{5}{c}{ Nastran } \\
& V12 & V15 & V16 & V12 & V15 & V16 \\
\hline Shells & 19,968 & 25,584 & 31,200 & 28,860 & 24,804 & 30,264 \\
Rigid bars & 6,280 & 7,850 & 9,420 & 7,057 & 7,066 & 8,479 \\
Solids & 2,496 & 3,120 & 3,744 & - & - & - \\
\hline Axial length & 156 & 156 & 156 & 195 & 156 & 156 \\
Stiffener bay & 16 & 16 & 16 & 24 & 16 & 16 \\
(between flanges) & 4 & 4 & 4 & 3 & 3 & 3 \\
Stiffener height & 8 & 8 & 8 & 8 & 8 & 8 \\
Stiffener flange & & & & & & \\
\hline
\end{tabular}

Table 3: Fracture toughness values used, from literature

\begin{tabular}{lll}
\hline Property & Fracture toughness $(\mathrm{N} / \mathrm{mm})$ & Reference \\
\hline$G_{\text {Ic }}$ & 220 & {$[7]$} \\
$G_{\text {IIc }}$ & 630 & {$[8]$} \\
\hline
\end{tabular}

Table 4: Predicted failure loads and locations

\begin{tabular}{|c|c|c|c|c|c|c|c|}
\hline Panel & $\begin{array}{l}\text { Power } \\
\text { expone }\end{array}$ & & $\begin{array}{l}\text { Failure axial } \\
\text { compression }(\mathrm{mm})\end{array}$ & $\begin{array}{l}\text { Failure } \\
\text { load }(\mathrm{kN})\end{array}$ & $\begin{array}{l}\text { Stiffeners for } \\
\text { failure }\end{array}$ & $\begin{array}{l}\text { Lengthwise } \\
\text { location }(\mathrm{mm})\end{array}$ & $\begin{array}{l}\mathrm{G}_{\mathrm{I}} / \mathrm{G}_{\mathrm{II}} \text { at } \\
\text { failure }\end{array}$ \\
\hline \multirow{2}{*}{ V12 } & $m=1$ & $n=1$ & 1.44 & 88 & $1 \mathrm{~L}, 4 \mathrm{U}$ & 472 & 1.6 \\
\hline & $m=0.2$ & $n=1$ & 1.35 & 94 & $1 \mathrm{~L}, 4 \mathrm{U}$ & 472 & 1.6 \\
\hline \multirow{2}{*}{ V15 } & $m=1$ & $n=1$ & 1.39 & 88 & $3 \mathrm{U}, 3 \mathrm{~L}$ & 390,415 & 1.8 \\
\hline & $m=0.2$ & $n=1$ & 1.28 & 86 & $3 \mathrm{U}, 3 \mathrm{~L}$ & 390,415 & 1.8 \\
\hline \multirow{2}{*}{ V16 } & $m=1$ & $n=1$ & 1.44 & 106 & $3 \mathrm{U}, 4 \mathrm{~L}$ & 465,320 & 1.4 \\
\hline & $m=0.2$ & $n=1$ & 1.20 & 100 & $3 \mathrm{~L}$ & 400 & 1.0 \\
\hline
\end{tabular}


Table 5: Redux 312 material properties, from literature

\begin{tabular}{ll}
\hline Property & \\
\hline$E_{1}(\mathrm{MPa})$ & 3000 \\
$v_{12}$ & 630 \\
Max. Compressive Stress $(\mathrm{MPa})$ & 48 \\
Max. Shear Stress $(\mathrm{MPa})$ & 38 \\
Max. Normal Stress $(\mathrm{MPa})$ & 8 \\
\hline
\end{tabular}

